\title{
Endovascular intervention to a rare cause of hematuria: Nutcracker syndrome - A case report
}

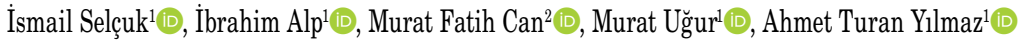 \\ ${ }^{1}$ Department of Cardiovascular Surgery, Sultan Abdulhamid Han Training and Research Hospital, Istanbul, Turkey \\ ${ }^{2}$ Department of Cardiovascular Surgery, Bayburt State Hospital, Bayburt, Turkey
}

Received: April 11, 2018 Accepted: May 09, 2018 Published online: April 24, 2019

\section{ABSTRACT}

Nutcracker phenomenon is described as the compression of the left renal vein between the superior mesenteric artery and aorta. Nutcracker syndrome (NCS) refers to clinical manifestations of the Nutcracker phenomenon. Although asymptomatic cases do not often require any intervention, symptomatic cases can be treated with medial nephropexy and excision of the renal varices, left renal vein bypass, transposition of the left renal vein, or stent placement in the left renal vein. Herein, we present a case with NCS and its management with endovascular intervention.

Keywords: Endovascular approach, Nutcracker syndrome, renal vein.

Nutcracker phenomenon is described as the compression of the left renal vein between the superior mesenteric artery and aorta characterized by renal vein stenosis at the level of the compression, increased renal vein compression, and renal vein dilatation proximal to the compression site. Infrequently, however, this phenomenon may occur at the retroaortic or circumaortic region due to the unusual course of the left renal vein. ${ }^{[1]}$

Nutcracker syndrome (NCS) refers to the symptoms and findings of hematuria, orthostatic proteinuria, pelvic congestion, varicocele, and flank pain due to the increased left renal vein compression. ${ }^{[2]}$ Although asymptomatic cases do not often require any intervention, symptomatic cases can be treated with medial nephropexy and excision of the renal varices, left renal vein bypass, transposition of the left renal vein, or stent placement in the left renal vein. ${ }^{[3]}$ Herein, we present a case with NCS and its management with endovascular intervention.

\section{CASE REPORT}

A 20-year-old female patient was admitted to our hospital with persistent fatigue, dark colored urination, and severe left flank pain lasting for four months. Her medical history revealed blood transfusion for two times due to severe anemia. The laboratory tests for urine and blood examination showed macroscopic hematuria, proteinuria, a hemoglobin level of $8.26 \mathrm{~g} / \mathrm{dL}$, and a hematocrit level of $22.5 \%$. Computed tomography angiography revealed compression of the left renal vein between the superior mesenteric artery and aorta. Additionally, a dilated venous segment was noticed proximal to the compression site (Figure 1). According to the workup performed at our clinic, the patient was diagnosed with NCS and an elective surgical intervention was planned. However, considering the young age of the patient and her aesthetic concerns, minimally invasive left renal vein stent implantation using an endovascular approach was decided.

A written informed consent was obtained from the patient. Initially, a $6 \mathrm{~F}$ sheath was inserted to the right common femoral vein to access to the left renal vein through the inferior vena cava. The left renal vein was passed via an 0.035-inch guidewire and the lesion

Corresponding author: Murat Uğur, MD. Sultan Abdulhamid Han Eğitim ve Araştırma Hastanesi Kalp ve Damar Cerrahisi Kliniği, 34668 Üsküdar, İstanbul, Turkey. Tel: +90 216 - 5422000 / 4055 e-mail: drmugur@gmail.com

\section{Citation:}

Selçuk İ, Alp İ, Can MF, Uğur M, Yllmaz AT. Endovascular intervention to a rare cause of hematuria: Nutcracker syndrome - A case report. Cardiovasc Surg Int 2018;5(2):33-35. 

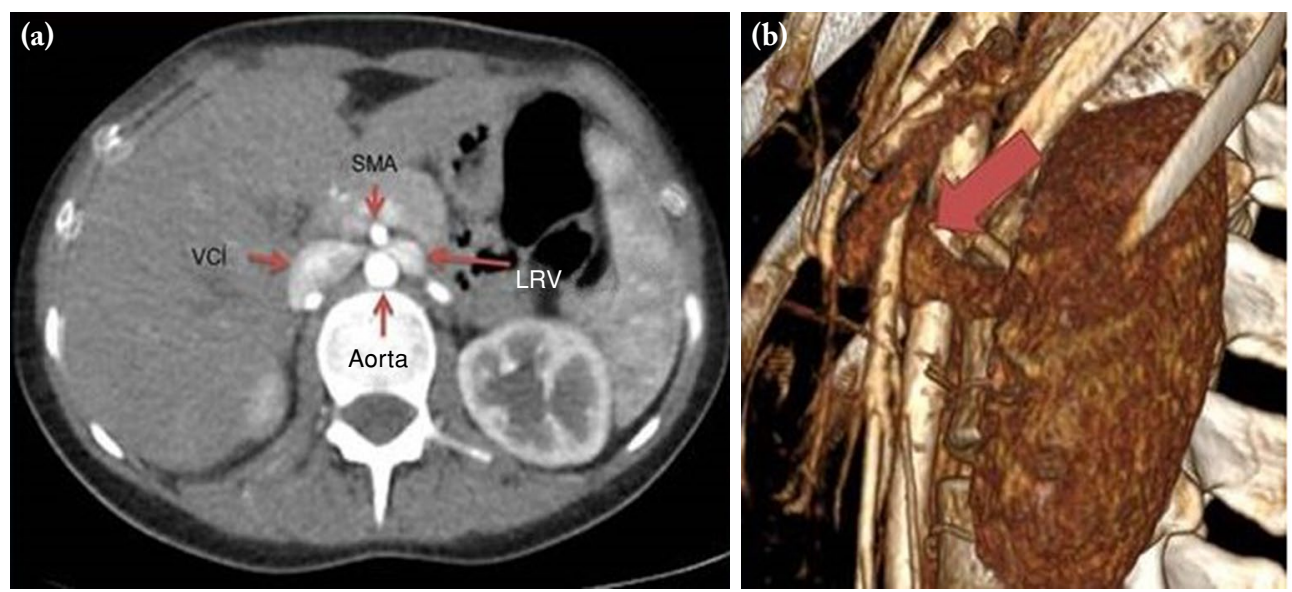

Figure 1. A computed tomography angiography showing the left renal vein compression at (a) transverse plane and (b) three-dimensional plane. SMA: Superior mesenteric artery; VCI: Vena cava inferior; LRV: Left renal vein; Ao: Aorta.

was predilated with a $10-\mathrm{mm} \times 4-\mathrm{cm}$ balloon catheter, followed by a $14-\mathrm{mm} \times 40$-mm self-expanding stent implantation. The procedure was terminated, when control angiography demonstrated the elimination of stenosis (Figure 2). On the postoperative second day, macroscopic hematuria disappeared as confirmed by the urinalysis which showed no evidence of microscopic hematuria. In addition, the hemoglobin and hematocrit levels return to normal range on the postoperative third day. The patient was discharged with complete recovery.

\section{DISCUSSION}

Nutcracker syndrome should be kept in mind in the differential diagnosis of hematuria in young adults due to its life-threatening complications, although it is a rare entity. It can cause recurrent hematuria episodes, leading to severe anemia requiring multiple blood transfusions in younger patients, as seen in our case.

Traditionally, NCS was treated with major surgeries, such as medial nephropexy with excision of dilated veins, left renal vein bypass, and left renal vein transposition. However, these procedures are currently preferred in limited, clinically symptomatic cases due to associated complications and low patency rates of renal vein bypass surgery. In recent years, a higher number of cases has been treated with endovascular surgery with higher rates of experiences with advanced surgical techniques. Therefore, renal vein stent implantation has become the first-line
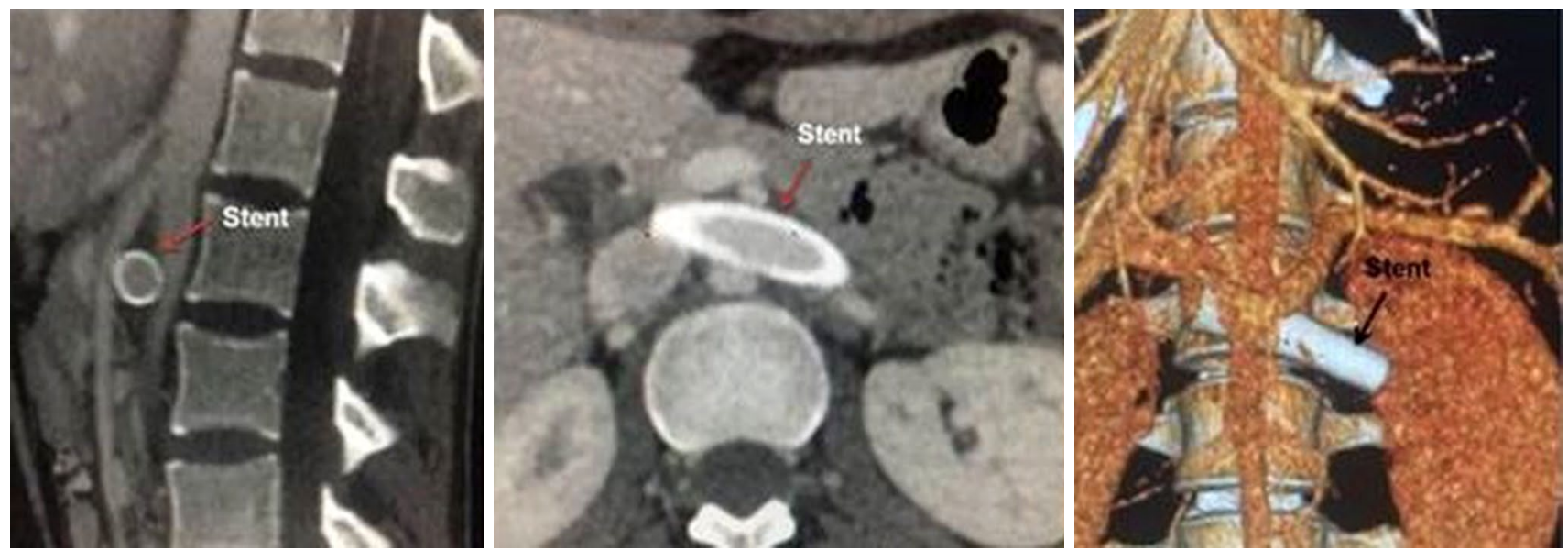

Figure 2. Postoperative angiography showing stent and renal vein. 
procedure in the treatment of NCS. ${ }^{[4]}$ Furthermore, a shorter duration of symptomatic improvement in the postoperative period and promising long-term patency rates of the stents encourage clinicians to treat NCS at earlier stages.

In the conventional approach to the NCS, most of the patients have been untreated still complications are developed. With the increased awareness of endovascular options for the treatment of the NCS, patients might be treated in the earlier stages of the disease. This treatment option will improve life quality of the patients before the symptoms occurred.

\section{Declaration of conflicting interests}

The authors declared no conflicts of interest with respect to the authorship and/or publication of this article.

\section{Funding}

The authors received no financial support for the research and/or authorship of this article.

\section{REFERENCES}

1. Ali-El-Dein B, Osman Y, Shehab El-Din AB, El-Diasty T, Mansour O, Ghoneim MA. Anterior and posterior nutcracker syndrome: a report on 11 cases. Transplant Proc 2003;35:851-3.

2. Shin JI, Lee JS. Nutcracker phenomenon or nutcracker syndrome? Nephrol Dial Transplant 2005;20:2015.

3. Marone EM, Psacharopulo D, Kahlberg A, Coppi G, Chiesa R. Surgical treatment of posterior nutcracker syndrome. J Vasc Surg 2011;54:844-7.

4. BarilDT, Polanco P, Makaroun MS, Chaer RA. Endovascular management of recurrent stenosis following left renal vein transposition for the treatment of Nutcracker syndrome. J Vasc Surg 2011;53:1100-3. 